\title{
Por que não existiram grandes cineastas mulheres no Brasil?*
}

Karla Holanda**

\section{Resumo}

Inspirada no ensaio "Why have there been no great female artists?", a comunicação se propõe a pensar algumas atualizações das discussões trazidas pelo texto de Linda Nochlin, publicado originalmente em 1971, adaptando o diálogo ao contexto cinematográfico brasileiro até a década de 1970, quando grandes cineastas brasileiros já estavam canonizados pela história do cinema. Por que não há mulheres nesse cânone do cinema no Brasil? O que constitui um grande cineasta? É sobre essas questões que este trabalho vai se debruçar ao enfrentar a afirmação embutida na pergunta do título.

Palavras-chave: Autoria feminina, Gênero, Cinema, Artes, Genialidade.

* Recebido em 24 de janeiro de 2019, aceito em 12 de maio de 2020.

** Professora do Programa de Pós-graduação em Cinema e Audiovisual (PPGCine) e da graduação em Cinema, ambos da UFF, Niterói, RJ, Brasil. holanda.k@gmail.com / https://orcid.org/0000-0003-2753-7679 
Why Have There Been no Great Female Filmmakers in Brazil?

\begin{abstract}
Inspired by the essay "Why have there been no great female artists?", this article considers some current issues found in discussions raised in the text by Linda Nochlin, first published in 1971, adapting the dialogue to the Brazilian cinema context until the 1970s, when great male Brazilian filmmakers had already been canonized in cinema history. Why have there no women in this canon of Brazilian cinema? What constitutes a great filmmaker? This study examines these questions by exploring the affirmation implied by the question in the title.
\end{abstract}

Keywords: Female Authorship, Gender, Cinema, Arts, Geniality. 


\section{A Pergunta}

A afirmação embutida na pergunta do título deste texto nos leva - reflexo imediato - a contestá-la, alegando que sim, houve grandes mulheres cineastas no Brasil, a história é que as omitiu. Quando Linda Nochlin fez a pergunta em seu célebre ensaio de 1971, "Why have there been no great female artists?", que tomo aqui como central para estabelecer um diálogo com o cinema no Brasil, ela previa que a primeira reação feminista à pergunta seria cair na armadilha de desenterrar uma série de exemplos de artistas mulheres que foram ignoradas ou insuficientemente reconhecidas ao longo da história, e sair "reabilitando carreiras mais modestas".

De certa forma, é o que pesquisas recentes no Brasil sobre mulheres no cinema têm feito: nos últimos anos vemos emergir um significativo número de cineastas que desconhecíamos totalmente ou das quais quase nada sabíamos, diante das tantas leituras e interpretações que se mostram possíveis a partir de suas obras, cujas análises têm iluminado aspectos históricos e estilísticos que se preservavam obscurecidos até então. Dentre algumas dessas cineastas, umas já bem conhecidas, outras menos, podemos citar Olga Futemma, Lili Bandeira, Luna Alkalay, Vera de Figueiredo, Adélia Sampaio, Gilda Bojunga, Ana Maria Magalhães, Maria do Rosário Nascimento e Silva, Helena Solberg, Ana Carolina, Suzana Amaral, Eunice Gutman, Katia Mesel - e tantas mais, mesmo ficando só com as que iniciaram suas carreiras entre os anos 1960 e 1970, não recuando aos anos anteriores ao cinema novo, tampouco chegando aos anos mais próximos.

Essas pesquisas demonstram o quanto a história canônica do cinema não considerou a produção feminina na mesma medida que a masculina, tomando essa como a universal. $\mathrm{O}$ esforço delas vale por trazer conhecimento, não apenas sobre a história do cinema feito por mulheres, mas também sobre a história do cinema geral, afinal, as lacunas também são revelações históricas. Entretanto, trilhando o raciocínio de Nochlin, essas iniciativas não respondem aos pressupostos implicados na pergunta "Por que não existiram grandes cineastas mulheres no 
Brasil?". A mesma pergunta caberia se substituíssemos "mulheres" por "afrodescendentes". Como diz Nochlin:

As coisas como estão, e como foram antes, nas artes e em centenas de outras áreas, são estupidificantes, opressivas $e$ desestimulantes para todos aqueles que, como as mulheres, não tiveram a boa sorte de nascer brancos, preferencialmente, de classe média e, sobretudo, homens. A culpa não é dos astros, dos nossos hormônios, dos nossos ciclos menstruais, dos nossos espaços internos vazios, mas das instituições e da nossa educação (Nochlin, 2017:19).

A surpresa, na verdade, é que, apesar das adversidades enfrentadas por mulheres ou negros, ainda haja tantos deles que se sobressaiam em territórios tidos como inerentes aos homens brancos, como a ciência, a política e as artes (Nochlin, 2017:19) e como, dizemos nós, na direção de filmes, principalmente quando essa pressupõe rentabilidade ou prestígio - basta lembrar que na década de 1960, aquela em que o cinema novo brasileiro recebe mais honras internacionalmente, praticamente não houve mulheres na direção de longas no país, mesmo tendo-se registro de, pelo menos, oito filmes com direção feminina nas décadas anteriores (Holanda, 2017:47).

É quando pensamos nas implicações da pergunta do título que nos damos conta do quanto nossa consciência está condicionada pela maneira como as questões importantes são formuladas, como adverte Nochlin. Ao lançar o provocativo título "Por que não existiram grandes artistas mulheres?", a autora tinha noção de que tal pergunta, traiçoeiramente, já insinuava a própria resposta: ora, "não há grandes artistas mulheres porque elas são incapazes de grandeza" (Nochlin, 2017:17). As "questões", continua, "são rapidamente formuladas para racionalizar a má consciência daqueles que detém o poder" - é preciso saber quem está formulando essas questões e, em seguida, quais suas intenções. Assim, podemos pensar que a "questão da pobreza" [ou "questão do negro" ou "questão do indígena" ou "questão do homossexual"], termo comumente usado por quem não é pobre 
[ou negro ou indígena ou homossexual], poderia ser mais diretamente colocada como "questão da riqueza", se formulada pelos moradores de guetos, por exemplo. Da mesma forma, a "questão da mulher" não deveria ser vista pela perspectiva da elite masculina dominante, mas realisticamente apropriada pelas mulheres - não se deve, afinal, esperar que a maioria dos homens entenda que é de seu interesse conceder igualdade às mulheres; os que têm privilégios costumam se agarrar a eles - é preciso, segundo Nochlin, uma mudança radical de postura das próprias "questões". São as mulheres que precisam enfrentar os fatos de sua situação, "sem autocomiseração ou subterfúgios" (Nochlin, 2017:19-20). Daí ser a própria autora a fazer a questão e ela própria a buscar respostas.

\section{Construindo gênios}

Se nas artes em geral é evidente, historicamente, aceitar a "grandeza" de, digamos, Michelangelo, Rembrant, Courbet, Giotto, Cézanne, Van Gogh, Rafael, Monet, Matisse, Picasso, no contexto do cinema brasileiro também se tem evidência similar. Nesse universo, sobretudo referente ao período da afirmação do cinema moderno brasileiro, se elencarmos Nelson Pereira dos Santos, Glauber Rocha, Joaquim Pedro de Andrade, Cacá Diegues, Ruy Guerra, Paulo Cezar Saraceni, Leon Hirszman, Rogério Sganzerla, provavelmente não seremos questionados nessa lista de "grandeza" do cinema nacional: trata-se de atestado dado pelos inúmeros textos acadêmicos e críticos dedicados a eles enquanto se firmava o cânone da história do cinema no Brasil.

Para além das inquestionáveis capacidades de todos esses artistas e cineastas, o que nos interessa, nesse momento, é a noção de "genialidade" embutida na ideia de "grande artista". E, ao pensar a mulher como cineasta, somos levadas a encontrar o mito do "grande artista", como acredita Nochlin em relação à mulher artista (Nochlin, 2017:21). Uma pergunta crucial e poucas vezes feita: quais as condições que geralmente produzem a grande arte? 
Entendendo a genialidade como um poder sobrenatural, atemporal e misterioso, o ensaio de Nochlin cita casos de artistas que tiveram seus talentos profetizados desde a infância, como se verifica em fatos narrados por seus biógrafos. O historiador Vasari imortalizou o jovem Giotto, ao contar que este foi descoberto na infância por um grande artista que o tomou como pupilo ao se impressionar com seus desenhos de ovelhas feitos numa pedra, enquanto esperava seu rebanho. Por uma estranha coincidência, outros artistas também foram descobertos depois em "circunstâncias pastorais similares", dentro do que a autora denomina "conto de fadas do artista descoberto por um artista mais velho". Outras façanhas encontradas que "atestam" poderes divinos desde tenra idade, são desenhos encontrados nas margens dos cadernos de muitos artistas ainda crianças, ao invés de indícios de estudo das matérias escolares, como se rabiscos semelhantes não estivessem também presentes em cadernos de inúmeros anônimos que exerceriam profissões banais. Ou o caso do jovem Picasso que, como já disseram, aos 15 anos, em um só dia, passou em dois difíceis exames de admissão, quando a maioria dos candidatos precisava de um mês de preparação. $\mathrm{O}$ que a autora põe em relevo é a falta de interesse em se investigar, por exemplo no caso de Picasso, quantos outros artistas também se qualificaram precocemente e foram medíocres artisticamente; ou, tampouco, há interesse em explorar o papel que o pai de Picasso, que era professor de arte, teve na formação do filho (Nochlin, 2017:21-2). Em outros termos, boas perguntas sugeridas por Nochlin a um historiador sério seria: se, ao invés de Pablo, Picasso fosse... Pablita? Ou de quais classes sociais brota a maior parte dos artistas? Ou quais têm pais artistas? Há muitas décadas, afinal, que se entende que as relações sociais são produzidas nas interseções de gênero, classe e "etnicidade" (Buscatto, 2016). Somente com essa compreensão, é que podem vir à tona as formas como são produzidos e repetidos os desequilíbrios originados pelas diferenças sexuais no meio artístico. 


\section{Obstáculos à grandeza}

Nochlin lembra que, assim como as mulheres, aristocratas também não costumam figurar entre os "grandes" - ambos até foram "encorajados a se aventurar nas artes e até a se tornarem amadores respeitados", mas alcançar aquele "a mais", era raro. O que há na constituição dessas categorias que as tornam impermeáveis a esse diferencial da "genialidade artística"? Não seria mais plausível atribuir essa impermeabilidade a demandas e expectativas colocadas para esses grupos que os impedem de dedicação integral à arte - funções sociais, no caso da aristocracia, e funções domésticas, no caso das mulheres, além da expectativa de contidas e recatadas posturas nos dois grupos? (Nochlin, 2017:24).

Funções domésticas têm influência estreita nas trajetórias das mulheres e quanto mais décadas atrás, maior era o impacto. Dois breves casos: a cineasta Olga Futemma, que realizou cerca de cinco curtas entre 1974 e 1989, interrompeu sua carreira no auge da criatividade, depois de lançar seu filme mais conhecido Chá verde e arroz (1989), para se dedicar a funções técnicas e de gestão, ${ }^{1}$ funções que lhes garantiriam maior estabilidade financeira, uma vez que estava com dois filhos crianças. Em entrevista realizada com ela, em 2016, eram frequentes referências a questões maternais e domésticas para lembrar de sua trajetória: "Eu só lembro do [set do meu filme] Retratos de Hideko com o Fernandinho ainda no 'Moisés' - a cadeirinha dele -, e que minha amiga ficava cuidando dele enquanto eu filmava"; ou "Fernando tinha 6 meses, o Bruno, dois anos e pouquinho, então não era uma operação muito simples" (Futemma apud Holanda, 2020:180).

1 Olga Futemma trabalhou na Cinemateca Brasileira desde 1984, tendo assumido a coordenação do centro de documentação e pesquisa, a direçãoadjunta e chegando ao cargo máximo, coordenação-geral, em 2015. É um nome-emblema no Brasil quando se fala de preservação audiovisual. Não se faz aqui, evidentemente, juízo sobre o que vale mais: se trabalhar com direção ou preservação de filmes. A intenção do comentário é enfatizar a função da direção como a que viria da "genialidade artística". 
Da mesma maneira, Eliane (Lili) Bandeira, que entre 1976 e 1982 dirigiu quatro curtas antenados com questões de seu tempo, com sofisticada estrutura de roteiro, produção e grande elenco. A diretora acabou se dedicando mais à função de produção e depois se tornou dona de restaurante. Só em 2012, voltou a dirigir outro curta. Lili sempre soube que ter filhos seria limitador na sua carreira:

Eu não queria ter uma família numerosa, porque eu sabia que profissão eu tinha escolhido. E ter filho não iria interromper minha profissão, isso eu tinha certeza. Mas eu sabia a doideira que era já. Quando o Lucas nasceu eu estava com vinte e sete anos, já tinha dirigido dois curtas, já tinha produzido um longa, já tinha feito assistência de direção... Eu sabia a intensidade. Então eu passei muitos anos da infância do Lucas com culpa muito grande (...). houve períodos que eu estava filmando em São Paulo, com o Lucas pequeno, quatro, cinco anos. Eu chegava em casa, tipo meia noite, uma hora, e saia às sete. Então eu só via o Lucas dormindo, eu nunca via o Lucas acordado, era uma coisa complicada (Bandeira, 2016).

Para Nochlin, se grandes conquistas são, de fato, raras, tornam-se ainda mais, se necessário - além dos monstros exteriores, revelados nos frequentes desencorajamentos -, ter que também enfrentar no seu trabalho os demônios interiores da culpa com as quais muitas têm que lidar. Culpa, por exemplo, ao devotar menor atenção aos filhos, ao marido e à casa, por se dedicar a uma carreira profissional.

Assim como para escrever ficção é necessário ter dinheiro e um teto todo seu, como defende Virgínia Woolf (1990), para filmar não seria diferente, inclusive no Brasil no período em que se canonizaram seus grandes cineastas. As mulheres de classes média e alta eram preparadas para casar, ter filhos e cuidar dos assuntos domésticos, portanto, não tinham ambiente propício à criação, menos ainda se fosse fora de casa, e como em geral, não exerciam atividade remunerada, eram dependentes financeiramente. Raras 
delas recebiam apoio familiar ao tentar escapar da fatalidade; outras arcavam sozinhas com o ônus da ousadia. Dois casos emblemáticos na história de nosso cinema: para poder dirigir seu único filme, Inconfidência mineira (1948), Carmen Santos criou seu próprio estúdio e se tornou produtora, e Cléo de Verberena que, junto com o marido, também bancou a produção de seu único filme, O mistério do dominó preto (1930), tido como o primeiro filme com direção feminina no Brasil (Araújo, 2017).

Além do mais, não era incomum o desencorajamento da continuidade de carreiras femininas. Após o lançamento de seu filme, Verberena, que era também atriz, função aceita pelos críticos para uma mulher na época, recebe comentário que não se pode dizer que tenha sido exatamente encorajador para que continuasse a dirigir. $\mathrm{O}$ crítico diz que ela

não se saiu má de toda. $\mathrm{O}$ dirigir um filme e interpretar o papel feminino é de uma responsabilidade ímpar. Não é tarefa para qualquer pessoa. Requer estudos especiais. Assim sendo, embora notássemos erros na direção, não nos cabe condená-la. Poderemos dizer-lhe, isso sim, que foi ousada. Ao mesmo tempo aconselhamo-la a não repetir a façanha. Ela possui personalidade. Como artista poderá alçar grandes êxitos. Como diretora, não (Stopinsky, apud Araújo, 2017:21).

Poderíamos seguir falando sobre as trajetórias de cineastas como Gilda Bojunga, Eunice Gutman, Luna Alkalay e tantas outras que sublimaram ou restringiram sua realização profissional por desestímulo de enfrentar uma carreira considerada pouco adequada às mulheres - certamente, um dos maiores pedágios pagos para o sucesso do capitalismo, que acirra a divisão sexual do trabalho, confinando as mulheres ao trabalho reprodutivo, invisível e desvalorizado (Federici, 2017). 


\section{O papel das instituições em proibir ou estimular}

Se formos à história das artes, podemos recuar no tempo $e$ ver que o desestímulo é igualmente evidente: a Academia Imperial de Belas Artes, implantada no Rio de Janeiro, em 1826, e denominada Escola Nacional de Belas Artes (Enba) a partir do advento da República, não aceitava mulheres como alunas antes de 1892. As que insistiam em estudar tinham que bancar caros ateliês particulares, geralmente dirigidos por artistas da Enba, sendo o mais procurado o dos irmãos Henrique e Rodolfo Bernardelli, que eram professores da Escola, sendo que o segundo foi diretor por 25 anos da instituição (1890-1915), que era pública e gratuita - triste e oportunista paradoxo. Contudo, as mulheres podiam participar de exposições com suas obras, embora tenham sido, invariavelmente, consideradas "amadoras" pelos críticos da época, mesmo que já fossem formadas, veteranas ou mesmo premiadas (Simioni, 2016).

Ao discorrer sobre a importância do modelo nu na formação $e$ treinamento do artista, sobretudo até o século XIX, Nochlin realça que esses estudos eram essenciais no desenvolvimento de todo artista com aspiração de grandeza. No entanto, as jovens aspirantes a artistas, por proibição das escolas de arte, tinham completa indisponibilidade a qualquer modelo nu, fosse masculino ou feminino. Contradição cínica sobre regras de decência é o fato de uma mulher poder ser modelo nu para homens, mas ser impedida de participar do estudo e documentação de um homem nu (ou mesmo mulher) como modelo. Com esse exemplo simples de proibição do modelo nu às mulheres, Nochlin entra no $\mathrm{X}$ de sua tese: a resposta à pergunta "Por que não existiram grandes artistas mulheres?" não passa por natureza de genialidade, mas pela "natureza de dadas instituições sociais e o que elas proíbem ou estimulam nas distintas classes ou grupos de indivíduos" (Nochlin, 2017:25), demonstrando a universalidade da discriminação contra as mulheres que impede a devida preparação para se alcançar, sequer, a proficiência. 
Na França, assim como no Brasil, as mulheres não eram aceitas nos Salões como pintores profissionais, não podiam frequentar a Escola de Belas Artes e eram proibidas de participar de concursos importantes até o final do século XIX. Nesse último caso, era diferente do Brasil, que permitia participação em concursos, embora com tratamento diferenciado (Simioni, 2016). Com esses obstáculos, não se esperava perseverança ou maior compromisso delas; no máximo, um amadorismo modesto, "apropriado para uma jovem bem criada" (Nochlin, 2017:25-8). ${ }^{2}$

Simioni descreve o tratamento que críticos deram às mulheres artistas da segunda metade do século XIX ao início do $\mathrm{XX}$, no Brasil. Vale destacar um trecho de um dos mais conhecidos deles, Luiz Gonzaga Duque Estrada, em seu célebre livro "A arte brasileira", que, como informa a autora, só traz referências às artistas "em sua páginas finais (após os esquecidos e os mortos) $e$ mediante o subtítulo de amadores" (itálicos da autora). Ao escrever sobre Abigail de Andrade, diz o crítico: "os retratos e as paisagens que há exposto são verdadeiras vitórias para uma amadora, mas nestas obras ressente-se um pulso muito feminino, muito tímido..." (Simioni, 2016:192-3) - note-se a apaziguada naturalização do que seria inferior ("pulso feminino", "timidez") ao que costuma ser relacionado ao universo das mulheres. A autora destaca o consenso socialmente difundido na época de que as mulheres não eram dotadas de capacidade criativa, abstrata, $e$ gastavam toda energia com a maternidade, portanto, mulheres artistas eram vistas como "aberrações". Com isso, elas:

enfrentavam, além das limitações institucionais, este poderoso obstáculo: a própria crença de que estavam, por

\footnotetext{
2 No Brasil, a primeira mulher a ter aulas de modelo vivo (nu) foi a paraense Julieta de França, em 1896, na Enba. Artista, aliás, que transgrediu muitas expectativas de seu gênero, tendo sido a primeira mulher a ganhar uma bolsa no Brasil para estudar em Paris, onde teve seu talento de escultora - especialidade rara entre as mulheres - reconhecido por renomados mestres. Apesar disso e pela ousadia imprópria às mulheres de contestar - no caso, curadorias de mostras -, foi ignorada pela história da arte (Simioni, 2016).
} 
natureza, excluídas da possibilidade de realizarem grandes obras, originais - logo, de serem geniais. E isso justamente no século $[\mathrm{XIX}]$ em que mais se associou a imagem do artista à do gênio (Simioni, 2016:194). ${ }^{3}$

Nochlin demonstra que ser pouco convencional é [sobretudo foi] determinante para a carreira de uma artista mulher, é preciso ter certa dose de subversão para não se aprisionar aos papeis socialmente aprovados. Como ela diz:
É apenas ao adotar (mesmo que dissimuladamente) os atributos "masculinos" de determinação, concentração, insistência e dedicação a ideias e habilidades para seu próprio beneficio que as mulheres alcançam e continuarão alcançando o sucesso no mundo da arte (Nochlin, 2017:31).

Adotar atributos "masculinos" para fugir dos atributos "femininos" - prontamente menos valorizados -, parece, assim, se tornar um artifício para as mulheres alcançarem sucesso. Claro que as mulheres podem ter determinação, concentração $e$ insistência porque, afinal, esses atributos não são exclusivos de gênero algum. Mas, enfim, o propósito é que as mulheres sempre subvertam papeis para que sejam apreciadas? Certamente, esse artifício seria eficiente, mas, uma vez que não é possível aceitar que existam qualidades inerentes a um gênero, o que se torna

\footnotetext{
${ }^{3}$ Para que não se tenha a impressão de que instituições cometiam tais, digamos, "aberrações" contra as mulheres somente no passado, trago um caso recente, dentre inúmeros outros. Em agosto de 2018, foi noticiada a fraude da Universidade de Medicina de Tóquio que, no processo de admissão, há mais de uma década, vinha inflacionando notas de candidatos homens, a fim de diminuir o número de candidatas aceitas, sob a justificativa de que elas teriam mais chance de abandonar a profissão em função de eventual maternidade. Não bastava a muitas dessas jovens enfrentar o desestímulo dentro da família para ousar em suas pretensões profissionais; a aptidão de muitas delas foi desperdiçada por determinação institucional - esse foi o inimigo maior. [https:/www.publico.pt/2018/08/08/mundo/noticia/inquerito-no-japao-provaque-universidade-prejudicava-candidatas-1840449 - acesso em 18 ago. 2018].
} 
urgente enfrentar é a ideia de que determinadas características são inferiores por, supostamente, pertencerem ao domínio feminino.

Buscatto apresenta algumas pesquisas realizadas na França nas últimas décadas que demonstram como determinados processos sociais no meio das artes produzem determinadas orientações sexuadas das práticas culturais - as mulheres tendem a se orientar às práticas "femininas" $e$ os homens às práticas "masculinas", sendo que os registros "femininos" costumam ter bem menos prestígio. Pesquisas revelam que alguns instrumentos musicais são predominantemente executados por mulheres $e$ outros por homens, ou seja, existem orientações para um ou outro instrumento, de acordo com o sexo. Essa orientação, diz a autora, se situa "tanto nas socializações de gênero atuando desde a pequena infância, quanto nos modos de organização das práticas da vida adulta" - qualquer transgressão do que seria o "natural" dessas práticas, custa muito caro socialmente, incorrendo no risco da estigmatização. E, claro, as práticas têm hierarquizações, que tendem a desvalorizar o que é relacionado ao "feminino". Ilustrativo o caso do jazz francês, onde $92 \%$ dos músicos são homens, enquanto as mulheres são maioria entre os cantores (65\%): não só as mulheres têm dificuldade de acesso aos instrumentos, como são diminuídas profissionalmente na função de cantar, em relação aos colegas instrumentistas. Para desmerecer a função, argumenta-se que a voz pertence ao corpo, é expressão natural, portanto, essa habilidade não merece tanto reconhecimento como a dos instrumentistas. Os homens cantores não experimentam o mesmo desmerecimento, uma vez que costumam ser também instrumentistas (Buscatto, 2016).

Por isso, Buscatto defende o estudo do agenciamento de gênero das práticas artísticas para que se percebam como são construídas as classificações artísticas $e$ os processos de legitimação cultural. A autora também ressalta como espaços artísticos também acolhem possibilidades transgressoras. Essas transgressões das normas de gênero podem se dar pela ação voluntária de certas artistas que lançam outras maneiras de criar muitas vezes, elas têm recursos superiores aos colegas, sejam 
contatos sociais, educação de alto nível e "genealogia familiar favorável" - aspectos que podem constituir uma "alavanca incomparável para se entender como algumas mulheres excepcionais conseguem se impor no mundo das artes, hostil às mulheres". Vale também considerar, ainda segundo Buscatto, como mundos da arte, por vezes, são tomados por "mudanças sociais que afetam as relações homens-mulheres", que tendem a abrigar novas formas de fazer arte, mais de acordo com os valores de seu tempo. Dessa forma, as mulheres podem encontrar mais espaço a partir de determinadas políticas públicas que levam a uma relativa desestabilização da ordem de gênero ao, por exemplo, se incentivar na França, nos anos 1980, a abertura de todas as escolas de arte também às artistas mulheres. $\mathrm{O}$ impacto da escola no desenvolvimento da carreira das mulheres, além de lhes conferir competência e confiança, lhes possibilita construir "laços sociais duradouros", quando estabelecem mais facilmente parcerias e interlocuções.

\section{Deslocando a noção de grandeza e novos parâmetros}

O ensaio de Nochlin será o gerador da chamada primeira fase da teoria e crítica feminista da arte (Barros, 2016: 45). No texto que escreverá 30 anos depois, "Why have there been no great women artists? Thirty years after", ela dirá que uma das metas do movimento de mulheres na arte foi deslocar a tradicional noção de "grandeza" da arte; ela admite que não estava conscientemente atenta em 1971 às "novas forças agenciadas na estratégia de eleição dos "gênios'" (Barros, 2016:20-21).

A originalidade e a inventividade, bases da noção de grandeza da modernidade, perdem centralidade, como afirma Roberta Barros, para outros parâmetros aos quais a obra de uma artista como Louise Bourgeois se aproxima: "o papel da biografia na interpretação no trabalho de arte $e$ a nova importância do abjeto, do informe, ou do poliforme/multiforme". Ou seja, novos padrões são eleitos, e esses coincidem com os aspectos que caracterizam a obra de Borgeouis. Com esses novos parâmetros 
em vista, o Museu de Arte Moderna de Nova York, no início da década de 1980, inaugura sua primeira retrospectiva com uma artista mulher, com itinerância por outros importantes museus nos Estados Unidos: "Louise Bourgeois: Retrospective". A artista, que já expunha desde os anos 1940, já com as mesmas propriedades que caracterizam sua obra citadas acima, passa a receber reconhecimento das instituições de arte e dos círculos acadêmicos dos Estados Unidos e da Europa (Barros, 2016:21-2).

Bourgeois não rompeu, necessariamente, algum papel, nem adotou outros valores: os parâmetros da boa arte é que mudaram e sua obra passou a ter importância. Nochlin conta exemplo semelhante, ao questionar o conceito de grandeza em seu ensaio, trazendo a pintora francesa Rosa Bonheur (1822-1899) como um estudo de caso que ilustra rara exceção de uma artista que se tornou proeminente no século XIX. De acordo com Nochlin, o sucesso da artista advém do período favorável em que ela se fez independente (meados do século XIX), quando uma mudança institucional favorece a vitória da "menos pretensiosa e mais livre pintura de gênero" sobre a tradicional pintura histórica, graças à ascensão da burguesia e consequente queda da aristocracia, o que aumentou o interesse por "pinturas menores, normalmente sobre assuntos do cotidiano". Portanto, "o naturalismo de Rosa Bonheur e sua habilidade de captar a individualidade - ou mesmo 'a alma' - de cada um dos animais que retratou coincidiu com o gosto burguês daquela época" (Nochlin, 2017:31-2). Ou seja, o estilo naturalista inspirado no cotidiano, marcante da obra de Bonheur, correspondeu aos parâmetros que seu tempo aspirava.

Entretanto, Nochlin, a despeito de ter percebido a ação das demandas de cada época na eleição dos "grandes", traiçoeiramente, demonstrou estar impregnada do conceito de grandeza do início dos 1970, pois, mesmo já sendo próxima de Louise Bourgeois nesse tempo, não questionou a ausência da artista dentro da instituição da arte. Afinal, a obra com a qual Bourgeois passaria a ser aclamada mundialmente no início dos 1980 já tinha sido produzida quando a ensaísta escrevera seu texto. Ela não parece ter visto os pressupostos que uma década 
depois fariam Bourgeois grande aos olhos das instituições de arte, assim como, retrospectivamente, ela viu as razões da "grandeza" de Rosa Bonheur. A "aura mágica" criada em torno dos "grandes", que alimenta mitos, não é percebida facilmente quando os indivíduos são mulheres; muitas vezes, nem mesmo as habilidades desenvolvidas passo a passo, que é, na verdade, o que faz o grande artista. Por outro lado, se o ensaio não tivesse sido escrito e, ao mesmo tempo, se fortalecia o corpo teórico decorrente do movimento de mulheres nessa década, será que as instituições de arte teriam alçado Bourgeois ao patamar de "grandeza"? (Barros, 2016:21). Isto é, as respostas que cada época pleiteia são reações a movimentos da própria época.

Nochlin não percebeu Bourgeois, que esperou que instituições - paradoxalmente, comandadas por homens atestassem sua obra. Em outros termos, seu pensamento promoveu mudanças sociais que resultaram em abertura de paradigmas, mas, no entanto, ela mesma não os anteviu, não os prenunciou. Isso nos faz lembrar de tantas cineastas que estavam aí ao lado e que passaram despercebidas pela história do cinema para além da força de seus filmes: se Os homens que eu tive (1973), de Tereza Trautman, tivesse sido realizado por Joaquim Pedro de Andrade, ou Feminino plural (1976), de Vera de Figueiredo, fosse de Glauber Rocha, ou, ainda, Amor maldito (1984), de Adélia Sampaio, fosse dirigido por Leon Hirszman, a história os teria ignorado, como, de fato, ignorou? A temática e a linguagem desses filmes correspondiam aos anseios de ruptura da época, mas a ideia de que mulheres cineastas pudessem ser criativas, não perdurava no horizonte por muito tempo. Mostra-se notório que uma das camadas mais onipresentes dos pressupostos de qualquer época é a soberania masculina. Com isso, realço a atenção que precisa ser redobrada para desnaturalizar a invisibilidade delas.

No meio das artes brasileiro se costuma argumentar que, diferente dos Estados Unidos, a história reconhece mulheres como grandes, como Tarsila do Amaral e Anita Malfatti, do movimento modernista da década de 1920. No entanto, de acordo com 
Roberta Barros, o reconhecimento dessas artistas só se dará na década de 1960, com a realização de leilóes em São Paulo, que fizeram emergir os modernistas como artistas de valor comercial (Barros, 2016:14). O crítico de arte Monteiro Lobato, em texto de 1917, não reconheceu especiais qualidades em "O torso" (19151916), pintura de Anita Malfatti que retrata um modelo masculino nu. Ao contrário, ao centrar sua crítica no que chamou de "caráter importado" da obra da pintora, nas "extravagâncias das vanguardas de "Picasso e companhia", o crítico desviou o debate "sobre a temática da sexualidade virilmente ali representada" (Barros, 2016: 50). Ao destacar que a escolha de Anita pelo modelo nu afirma a saída das mulheres do espaço doméstico e seu ingresso no ensino superior, Barros diz que Malfatti, "numa postura ativa, não condizente com o lugar da feminilidade, carregou a obra de erotismo em seus traços grossos e angulosos, (...) desafiou a ordem das coisas, ao colocar comedor em lugar de comida". Tal inversão de posições naquele momento foi, provavelmente, um dos fatores que retardou o reconhecimento "oficial e histórico" da artista, o que se daria só quatro décadas mais tarde (Barros, 2016:51).

Diante de algumas ações hoje que demonstram que o mundo visível das narrativas no cinema quase sempre corresponde ao do homem branco, heterossexual e rico, desenvolvem-se no meio da academia, da crítica e da curadoria, novas perspectivas e novos discursos que têm exigido novas respostas. Assim, narrativas recentes têm revelado qualidades em obras do passado que ficaram praticamente desconhecidas. $\mathrm{E}$, nesse percurso de revisão, ressaltando o cinema, de que vale tentar associar, como alguns sugerem aqui e ali, Helena Solberg ao Cinema Novo ou Luna Alkalay ao Cinema Marginal - ambas tendo realizado seus primeiros filmes na década de 1960? Ora, no tempo em que foram canonizados os "grandes" cineastas brasileiros, elas não foram relacionadas a esses movimentos, sequer ficaram para a história do cinema brasileiro, mesmo que estivessem ali, naquele momento, produzindo. Por que deveriam ser vinculadas depois de tantas décadas? Afinal, os valores que 
suas obras trazem aos olhos de hoje, nada valeram na época e o fato histórico desse apagamento não pode ser apagado novamente.

Nos últimos anos, quando vemos cobranças que evidenciam o desequilîbrio de gênero, raça, etnia e classe na representatividade dos filmes no Brasil, é que essas categorias se impõem como novos parâmetros, despertando interesse de festivais e de certos públicos. Podemos constatar olhares mais atentos, em especial de alguns festivais, críticas e academia mais interessados em ouvir seu tempo, ao que mulheres - sobretudo em suas camadas interseccionais - vêm produzindo, como se estivessem sendo delineados novos conceitos de "grandeza".

\section{Concluindo}

O que propus aqui foi trazer, até certo ponto, as discussões da historiadora da arte estadunidense, Linda Nochlin, em seu ensaio mais conhecido, mas buscando caminho próprio, ao considerar o cinema e o contexto brasileiro. Primeiramente, apesar de já ter se iniciado certa sistematização de pesquisas sobre cineastas mulheres no Brasil, através de pesquisas recentes que demonstram a invisibilidade ou pouca relevância histórica de cineastas ao longo do século $\mathrm{XX}$, a despeito de importantes significações que suas obras trazem, fiz breve relato desse panorama, que começa a receber alguma reparação da história. Enquanto podemos facilmente nomear alguns cineastas que se consagraram como "grandes" na história inscrita do nosso cinema, teríamos dificuldade em encontrar equivalências femininas em "grandeza". É evidente que as mulheres não são, naturalmente, impermeáveis a ela (assim como afrodescendentes e indígenas), mesmo que não tenham faltado, ao longo da história, justificativas, inclusive das ciências e das instituições, para legitimar a incapacidade feminina, sua impossibilidade de integrarse à esfera pública. $\mathrm{O}$ que vimos são pressupostos pautando demandas em cada época, determinando "grandezas", demonstrando que nenhuma "grandeza" ou "genialidade" é da 
ordem do sobrenatural, uma espécie de condição inerente desde sempre, que se manifesta em obras-primas. Daí a importância de promover discussões que contribuam para mudanças de modelos, como fez Nochlin em seu ensaio, e como se verifica em discursos nos últimos anos no Brasil que reivindicam representatividade mais equiparada de gênero, raça, etnia e classe, repercutindo na argumentação de curadorias e críticas.

Ao usar exemplos das artes, pintura, música, não pretendo estabelecer comparações dessas expressões com o cinema: o central é discutir a noção de grandeza. Tampouco é relevante, neste espaço, elencar "genialidades" femininas abafadas historicamente, mas perceber a aridez do meio para o desenvolvimento da própria existência das mulheres como sujeitos plenos. Se a partir daí surgiram grandes cineastas mulheres, já não tem sentido essa defesa. "Genialidade" é um constructo, ser "grande" implica uma escala comparativa e, como a história demonstra, é, no limite, colocar outros em posição subalterna. Almejar a categoria tradicional de "grandeza" é ratificar noções que sustentam mecanismos de domínio masculino em detrimento de outros associados ao universo feminino.

Exemplo ilustrativo recente é o documentário Democracia em vertigem (2019), de Petra Costa, em que a voz pouco projetada da diretora, um tanto incerta, hesitante, sem aspirar a verdades absolutas, foi muito criticada justamente por essas qualidades que, a mim parecem, constituir o elemento mais original da linguagem do filme, ao eliminar o tom autoritário da tradicional voz over do documentário. Essa voz miúda provoca um choque estético singular ao se deparar com o contexto histórico em que o filme foi produzido e lançado, quando vozes definitivas e taxativas das redes sociais, em especial, despejam um lamaçal de afirmações questionáveis, para dizer o mínimo, sob o manto de certezas incontestáveis. O estranhamento que a voz minúscula de Petra tem despertado - para além de outras críticas que, com justiça, o filme pode merecer -, se deve a expectativas viciadas por modelos de grandezas que vêm acompanhados de "qualidades viris", como assertividade, segurança, firmeza, 
valentia, objetividade. Estamos diante de um novo paradigma clamado por nosso tempo? Tais elementos que caracterizam essa voz subjetiva não postulam um conceito renovado de "grandeza"?

No entanto, não se pode perder de vista que se uns se tornam grandes é porque inúmeros silenciamentos foram promovidos. Ser grande na escala de sentido de se destacar da maioria, precisa cair no mau gosto da ideia tosca de ser melhor que outros; que sejam sempre eleitos novos paradigmas que permitam o convívio da diversidade, da pluralidade e diferenças. $\mathrm{O}$ que se pretende é o direito à visibilidade, o direito de ser; que antenas estejam alertas às placas tectônicas que se movem ao lado, que se tenham olhos para ver e também antever urgências de cada tempo.

\section{Referências bibliográficas}

ARAÚJO, Luciana Corrêa de. Cléo de Verberena e o trabalho da mulher no cinema silencioso brasileiro. In: HOLANDA, Karla; TEDESCO, Marina Cavalcanti (orgs). Feminino e plural: mulheres no cinema brasileiro. Campinas, SP, Papirus, 2017. pp. 15-29.

BARROS, Roberta. Elogio ao toque - ou como falar de arte feminista à brasileira. Rio de Janeiro, Editora do Autor, 2016.

BANDEIRA, Eliane. Eliane Bandeira: depoimento [16 de novembro, 2016, em São Paulo]. 1 arquivo áudio m4a. Entrevista concedida ao Projeto Documentaristas Brasileiras, financiado pelo CNPq Chamada Universal. Entrevistadora: Karla Holanda. Juiz de Fora: UFJF, 2016.

BUSCATTO, Marie. A arte segundo o ponto de vista do gênero: Ou revelar a normatividade dos mundos da arte. In: QUEMIN, Alain;

\footnotetext{
${ }^{4}$ Tais características da voz de Democracia em vertigem não são inéditas. Há inúmeros filmes que já as trazem, desde mesmo $A$ entrevista (1966), de Helena Solberg. Entretanto, nenhum desses filmes chegou tão longe em termos de visibilidade, como o filme de Petra Costa, que concorreu ao Oscar de Melhor documentário, em 2020, além de outras celebrações. A particularidade é que a expressividade que o filme alcançou permitiu emergir esse debate.
} 
VILLAS BÔAS, Glaucia. Arte e vida social: pesquisas recentes no Brasil e na França. Marseille, França, OpenEdition Press, 2016. Disponível em https://books.openedition.org/oep/1477. Acesso em 05/01/2019.

FEDERICI, Silvia. Calibã e as bruxas: mulheres, corpo e acumulação primitiva. São Paulo, Elefante, 2017.

HOLANDA, Karla. Pegadas do cinema de Olga Futemma. Lumina, v. $14, \quad$ n. 2, p. 171-185, 30 ago. 2020. Disponível em https://periodicos.ufjf.br/index.php/lumina/article/view/29758. Acesso em 08/10/2020.

HOLANDA, Karla. Cinema brasileiro (moderno) de autoria brasileira. In: HOLANDA, Karla; TEDESCO, Marina Cavalcanti (orgs). Feminino e plural: mulheres no cinema brasileiro. Campinas, SP, Papirus, 2017. pp. 43-58.

NOCHLIN, Linda. "Por que não existiram grandes mulheres artistas?". In: PEDROSA, Adriano; MESQUITA, André (orgs). Histórias da sexualidade: antologia. São Paulo, Masp, 2017. pp. 16-37.

SIMIONI, Ana Paula Cavalcanti. Os gêneros da arte: mulheres escultoras na belle époque brasileira. In: BUENO, Maria Lucia. Sociologia das artes visuais no Brasil (org.). São Paulo, Ed. Senac, 2012. pp. 185210.

WOOLF, Virginia. Um teto todo seu. São Paulo, Círculo do Livro, 1990. 